\title{
Atualidade do pensamento pedagógico de Paulo Freire em tempos de pandemia (Covid-19): enfrentamentos e (re)invenções
}

\author{
Luciana Miyuki Sado Utsumi*
}

\section{Resumo}

$\mathrm{O}$ artigo se propõe a revisitar o pensamento pedagógico de Paulo Freire, a fim de articulá-lo na compreensão e no enfrentamento do contexto da escolarização em tempos de pandemia (Covid-19). Tem como objetivo situar o pensamento pedagógico de Freire em função das demandas do tempo presente, de modo a lançar provocações e possibilidades para o futuro da escolarização. O recorte bibliográfico do pensamento pedagógico de Freire se põe em diálogo com estudiosos da obra freiriana, de maneira que podemos concluir que o pensamento pedagógico de Paulo Freire é atual e atemporal, uma vez que confere sustentação teórica e prática aos educadores com esperança por tempos de superação dos desafios em contextos pandêmicos e pós-pandêmicos de escolarização.

Palavras-chave: 1. Paulo Freire; 2. Covid-19; 3. Escolarização; 4. Formação de Educadores

\section{Actuality of Paulo Freire's pedagogical thinking in times of pandemic (Covid-19): confrontations and (re)inventions}

\section{Abstract}

The article proposes to revisit the pedagogical thinking of Paulo Freire, in order to articulate it in understanding and facing the context of schooling in times of pandemic (Covid-19). It aims to situate Freire's pedagogical

Doutora e Mestre em Educação pela Universidade Metodista de São Paulo UMESP. Pós-Doutorado em Educação pelo PPGE da Universidade Federal de Mato Grosso - UFMT. Docente de cursos de graduação em Pedagogia. Integrante do Grupo de Estudos Paulo Freire da Universidade Metodista de São Paulo - UMESP (desde 2004). Contato: luciana.sado@gmail.com 
thinking in terms of the demands of the present time, in order to launch provocations and possibilities for the future of schooling in the context of the pandemic. The bibliographical clipping of Freire's pedagogical thought is put into dialogue with scholars of Freire's work, so that we can conclude that Paulo Freire's pedagogical thought is current and timeless, as it provides theoretical and practical support to educators with hope for times of overcoming challenges in pandemic and post-pandemic schooling contexts.

Keywords: 1. Paulo Freire; 2. Covid-19; 3. Schooling; 4. Educator Training

\section{Actualidad del pensamiento pedagógico de Paulo Freire en tiempos de pandemia (Covid-19): enfrentamientos y (re) invenciones}

\section{Resumen}

El artículo propone revisar el pensamiento pedagógico de Paulo Freire, para articularlo en la comprensión y el enfrentamiento del contexto de la escolarización en tiempos de pandemia (Covid-19). Pretende situar el pensamiento pedagógico de Freire en términos de las demandas del momento presente, para lanzar provocaciones y posibilidades para el futuro de la escolarización en el contexto de la pandemia. El recorte bibliográfico del pensamiento pedagógico de Freire se pone en diálogo con los estudiosos de la obra de Freire, de modo que podemos concluir que el pensamiento pedagógico de Paulo Freire es actual y atemporal, ya que brinda apoyo teórico y práctico a los educadores con esperanza en tiempos de superación de los desafíos en contextos de escolarización pandémicos y pospandémicos.

Palabras clave: 1. Paulo Freire; 2. Covid-19; 3. Escolaridad; 4. Formación de educadores

\section{Introdução: enfrentamentos do processo de esco- larização em tempos pandêmicos}

Vivemos tempos pandêmicos... Vivemos tempos sem precedentes na história da nossa condição humana de existência. Vivemos tempos de crise em escala global, fato que nos coloca diante de fragilidades, problemas, desafios e enigmas que configuram o presente e o futuro da humanidade. De modo geral, Boff (1983 
apud SANTOS NETO, s/d, p. 01-02) não entende a crise como algo negativo, mas como uma possibilidade de criar novas respostas através de novas estruturas, novas opções e novos direcionamentos. "Vivemos um momento paradoxal: ao lado de grandes avanços impulsionados pela ciência e pela tecnologia, temos grandes ameaças à construção de uma existência plenamente humana para todos."

Sabemos que a pandemia não é neutra e tem alvos privilegiados, mas, paradoxalmente, cria-se com ela uma consciência de comunhão planetária, de algum modo democrática. A etimologia do termo pandemia diz isso mesmo: todo o povo. A tragédia é que, no caso da Covid-19, a melhor maneira de sermos solidários uns com os outros é isolarmo-nos uns dos outros e nem sequer nos tocarmos. "É uma estranha comunhão de destinos" (SOUSA SANTOS, 2020, p. 47).

O vírus Corona (Covid-19) ${ }^{1}$ é de índole democrática - "todo o povo" - confirmando a etimologia do termo pandemia, uma vez que não tem preferências de classe. Mas nós, em nossa condição humana, não somos democráticos. "De repente, nós lembramos que somos todos apenas seres humanos, com as mesmas vulnerabilidades, e fragilizar a saúde de uns gera a tragédia para todos" (DOWBOR, 2020, p. 115). Na esteira dessa problematização, sabemos que a Covid-19 tem outro traço irônico ou perverso, visto que não atinge a todos do mesmo modo.

Pode até ser sedutor o discurso de que estamos no mesmo barco, mas não é real. Habitamos o mesmo planeta, mas temos condições absolutamente desiguais de vida e, portanto, de reação a pandemias. [...] A doença não atingirá nossos corpos da mesma maneira. [...] Diante de tantas constatações, cada vez mais visíveis e irrecusáveis, a Covid-19 deveria nos impedir de seguir fingindo que a desigualdade social é uma fatalidade, em relação a qual não temos responsabilidade alguma. (SEVERO, 2020, p. 221).

1 Para saber mais: https://www.paho.org/pt/covid19/historico-da-pandemia-covid-19 (Acesso em: 15.06.2021). 
Paulo Freire nos alerta para a necessidade de nos pormos em relação de organicidade com nossa realidade, a fim de que possamos equacionar nossos problemas de forma crítica e consciente, haja vista que somente na medida em que nos fizermos íntimos de nossos problemas, sobretudo de suas causas e de seus efeitos, nem sempre iguais aos de outros espaços e de outros tempos, ao contrário, quase sempre diferentes, poderemos apresentar soluções para eles. Como se verifica, para Freire, tal relação de organicidade com uma realidade específica é fundamental, na medida em que nos mune de critérios e fundamentos para, antes de apresentar soluções, identificar uma experiência/vivência problematizadora. Nesse contexto, é fundamental e urgente,

reconhecer a desumanização, não apenas como viabilidade ontológica, mas como realidade histórica. É também, e talvez sobretudo, a partir desta dolorosa constatação que os homens se perguntam sobre a outra viabilidade - a de humanização. Ambas, na raiz de sua inconclusão, os inscrevem num permanente movimento de busca. Humanização e desumanização, dentro da história, num contexto real, concreto, objetivo, são possibilidades dos homens como seres inconclusos e conscientes de sua inconclusão. (FREIRE, 2005, p. 32).

Sendo inconclusos, tal condição humana nos inscreve na realidade histórica como seres humanos capazes de conhecer melhor a realidade e, conhecendo-a em suas raízes antropológica, epistemológica e política, transformá-la. Essa viabilidade ontológica nos coloca como seres humanos capazes de transformar a desumanização em humanização, por meio da libertação dos homens, haja vista que somente o homem, como um ser que trabalha, que tem um pensamento-linguagem, que atua e é capaz de refletir sobre si mesmo e sobre a sua própria atividade, que dele se separa. Somente o homem, ao alcançar tais níveis, se fez um ser da práxis. Somente ele vem sendo um ser de relações num mundo de relações. Dessa maneira, sua presença num tal mundo, presença que é um estar com, compreende um permanente defrontar-se com ele (FREIRE, 1977). 
Como um tempo de acontecimentos humanos, a história é feita pelos homens, ao mesmo tempo em que nela se vão fazendo também. E, se o que-fazer educativo, como qualquer outro que-fazer dos homens, não pode dar-se a não ser "dentro" do mundo humano, que é histórico-cultural, as relações homens-mundo devem constituir o ponto de partida de nossas reflexões sobre aquele que-fazer. (FREIRE, 1977, p. 76).

Nestes termos, para Freire (1996), seria impossível saber-se inacabado e não se abrir ao mundo e aos outros à procura de explicação, de respostas a múltiplas perguntas, na medida em que o fechamento ao mundo e aos outros se torna transgressão ao impulso natural da incompletude. Nesse sentido, o sujeito que se abre ao mundo e aos outros inaugura com seu gesto a relação dialógica em que se confirma como inquietação e curiosidade, como inconclusão em permanente movimento na História.

No que se refere ao contexto de desumanização, confirmado e reforçado pela Covid-19, urge refletirmos sobre tal questão:

Que potenciais conhecimentos decorrem da pandemia do coronavírus? A normalidade da exceção. A atual pandemia não é uma situação de crise claramente contraposta a uma situação de normalidade. [...] Por isso, a pandemia vem apenas agravar uma situação de crise a que a população mundial tem vindo a ser sujeita. Daí a sua específica periculosidade. (SOUSA SANTOS, 2020, p. 45-46).

$\mathrm{Na}$ esteira da denúncia desse contexto de periculosidade, o mesmo autor anuncia a necessidade de uma postura mais humilde da humanidade, por meio de uma nova articulação entre os processos políticos e os processos civilizatórios. Caso contrário, “o futuro desta quarentena será um curto intervalo antes das quarentenas futuras" (SOUSA SANTOS, 2020, p. 31).

Nesta direção, de acordo com Freire (1992), o sonho pela humanização, cuja concretização é sempre processo, e sempre devir, passa pela ruptura das amarras reais, concretas, de ordem econômica, política, social, ideológica etc., que nos estão condenando à desumanização. O sonho é assim uma exigência ou uma 
condição que se vem fazendo permanente na história que fazemos e que nos faz e re-faz. Vale dizer que o sonho possivel não se trata de uma idealização ingênua, mas emerge justamente da reflexão crítica acerca das condições sociais de opressão cuja percepção não se faz determinista, mas compreende a realidade como mutável a partir da participação dos sujeitos que a constituem, sendo igualmente por ela constituídos. Desse modo, "incluir-se na luta por sonhos possíveis implica assumir um duplo compromisso: o compromisso com a denúncia da realidade excludente e o anúncio de possibilidades de sua democratização, bem como o compromisso com a criação de condições sociais de concretização de tais possibilidades" (FREIRE, 2001, p. 28).

No contexto da Covid-19, testemunhamos que:

a educação também foi atingida pela emergência. De um dia para o outro, o ensino remoto substituiu a modalidade presencial, tornando-se a única forma de ensino. Esse ensino que é uma alternativa para substituir a modalidade presencial, em face ao isolamento social provocado pela pandemia do novo coronavírus (Covid-19), como consequência levou todos os níveis da educação para um mundo mediado pelas máquinas. (SILVA et al, 2020, p. 03-04).

A certeza de que nada voltará a ser como era antes não se aplica, na mesma proporção, para a projeção de que tudo pode ser melhor do que nunca foi... Vivemos em tempos de incertezas, de desafios múltiplos, de enfrentamento dos discursos fatalistas na área da Educação, no geral, e na educação escolar, em particular. Meses após meses, realizamos projetos de vida para o presente palpável e para um futuro incerto.

Outra tensão contemporânea que a sociedade vive no campo da educação está em tratá-la como um negócio, não como um direito do cidadão e uma ferramenta para desenvolvimento social e econômico do país. Afinal, uma educação tratada com um direito universal se contrapõe a um serviço, um bem econômico, que se organiza com uma empresa e busca rentabilidade e retorno do investimento. E com o coronavírus em 2020, a pandemia se tornou álibi para a degradação do trabalho do professor, em contraste 
com a valorização do ensino a distância: crise financeira e quarentena. (SILVA et al, 2020, p. 11-13).

Em outras palavras, "o neoliberalismo continua avançando, ganhando terreno na defesa de seus princípios e o projeto e a educação não fica alheio a essa conjuntura. A economia retoma o seu funcionamento, os setores privados da educação pressionam para o retorno às atividades" (COSTA, 2020, p. 09).

No entanto, é necessário destacar que, em algumas regiões do Brasil, a infraestrutura tecnológica apresenta falta de equipamentos básicos para o ensino e baixa velocidade de Internet, o que dificulta a formação de professores e, consequentemente, o aprendizado de crianças e jovens. [...] Não obstante a carência de recursos tecnológicos para a massa populacional brasileira, a tecnologia transforma constantemente a forma como aprendemos e ensinamos. (SILVA et al, 2020).

A ética para o neoliberal é algo que é reduzido simplesmente à ética do mercado. Por exemplo, como é possível que aceitemos o fato de que milhões de pessoas estejam desempregadas; será apenas uma fatalidade do final do século? Não se trata de uma fatalidade. Trata-se de um dos resultados da ética do mercado. Precisa ser compreendido que esta assim chamada fatalidade é também uma construção social informada pela ética do mercado. Deste modo, tornou-se necessário para os professores, especialmente professores críticos, destruir a construção social deste fatalismo, de modo a revelar a ideologia inerente que informa, configura e mantém uma ética da ganância. É por esta razão que nós, educadores democráticos, devemos lutar de modo a que se torne cada vez mais e mais claro que a educação representa formação e não treinamento. E não há nenhuma possibilidade de se obter formação humana fora da ética. Para mim, então, um dos requisitos do contexto histórico presente é que a formação ética dos professores deve acompanhar, deve ir de mãos dadas com a preparação profissional, científica e tecnológica de futuros professores e professoras de alfabetização. Os requisitos éticos estão se tornando cada vez mais críticos num mundo que está se tornando cada vez menos ético. Logo, nunca poderemos resolver realmente o problema da formação do professor e da professora com simples propostas tecnicistas, que é o que todos estão me pedindo para dar. [...] Um dos resultados do novo pragmatismo do 
neoliberalismo está mais relacionado com o treinamento técnico científico dos educadores por negar uma formação mais abrangente porque tal formação sempre exige uma compreensão crítica do papel de cada um no mundo. (FREIRE, 2001, p. 66-67).

Segundo Lima (et al, 2020), os estudos realizados sobre o período de suspensão das aulas presenciais trouxeram indicações inquietantes: a desigualdade nas condições de oferta educacional, de acesso e realização das atividades propostas nesse período de suspensão das aulas presenciais implica riscos de tornar o processo educacional não mais apenas um reflexo da desigualdade existente "lá fora" e sim, ele próprio, um fator que pode acirrar tais desigualdades. Conforme os mesmos autores, embora a interrupção das aulas presenciais tenha ocorrido praticamente ao mesmo tempo para todas as modalidades, etapas e redes,

as condições para interagir com propostas alterativas de atividades a serem realizadas em casa foi drasticamente desigual, em função de um amplo conjunto de fatores internos ou externos aos sistemas educacionais e iniquidades de distintas naturezas. Assim como, certamente, serão também desiguais suas consequências. (LIMA et al, 2020, p. 19).

Ao centrarmos o olhar na questão da Educação, ao mesmo tempo em que consideramos a sociedade na qual estamos inseridos, podemos constatar a enorme dificuldade para a construção e efetivação de uma pedagogia da solidariedade e da responsabilidade por parte dos profissionais do ensino, os/as quais, sem o conhecimento (ainda!) dos inúmeros fatores circunstanciais e contextuais constituintes da complexidade da/na função docente, acabam por imprimir concepções de Educação prejudiciais em suas práticas, ditas pedagógicas e/ou educativas.

$\mathrm{O}$ poder que o/a professor/a exerce sobre os alunos numa relação vertical de ensino e de aprendizagem, conferindo-lhe a sensação de controle da situação e/ou de alguém, este mesmo poder que oprime e anula o diálogo, enfim, o poder como forma de opressão, exercido indiscriminadamente no cotidiano de nossas escolas, con- 
figura-se numa pedagogia desumana e desumanizadora, em contraposição a uma pedagogia da esperança, dos sonhos possíveis, enfim, uma pedagogia da condição humana que prime por uma formação de educadores alicerçada nos princípios freireanos, que visam à constituição de seres pensantes, transformadores, criadores e realizadores de sonhos.

A esperança, para o professor, a professora, não é algo vazio, de quem "espera" acontecer. Ao contrário, a esperança para o professor encontra sentido na sua própria profissão, a de transformar pessoas, a de construir pessoas, e alimentar, por sua vez, a esperança delas para que consigam, por sua vez, construir uma realidade diferente, "mais humana, menos feia, menos malvada", como costumava dizer Paulo Freire. Uma educação sem esperança não é educação. A educação, nesse sentido, confunde-se com processo de humaniz̧ação. (GADOTTI, 2003, p. 45).

É esta fidelidade ao homem e ao humano que marcará para sempre a pedagogia freireana. E esta opção pelo humano, em Paulo Freire, "nasce do compromisso do homem e do pensador, com as grandes causas sociais, políticas e culturais (FREIRE, 1981) que marcaram e continuam a marcar os seus e os nossos tempos: a desigualdade de direitos e com ela a exclusão pessoal e social de muitos seres humanos" (MELRO, 2006, p. 03).

Neste sentido, acreditamos na necessidade e possibilidade de práticas pedagógicas mais humanas, emancipatórias e democráticas em níveis escolares e, portanto, ressaltamos a necessidade da viabilização de uma formação integral dos(as) professores(as), que promova a agregação das relações pessoais. Mas, de que formação integral dos(as) professores(as) estamos a nos referir? Defendemos uma formação integral cujos aspectos e concepções diversos se encontram intimamente imbricados e são/estão subjacentes às práticas escolares no processo de ensino e de aprendizagem, tal qual enuncia Freire (2000, 1996, s/p): “Jamais pude pensar a prática educativa...intocada pela questão dos valores, portanto da ética, pela questão dos sonhos e da utopia, quer dizer, das opções políticas, pela questão do conhecimento e da boniteza, isto é, da gnosiologia 
e da estética." Uma legítima pedagogia da condição humana que se configura um desafio complexo, enquanto profissionais do ensino, por uma maior humanização em todas as relações interpessoais, especificamente das relações pedagógicas.

A par das considerações apresentadas, o presente artigo se propõe a revisitar o pensamento pedagógico de Paulo Freire, a fim de articulá-lo na compreensão e no enfrentamento do contexto da escolarização em tempos de Covid-19. Tem como objetivo situar o pensamento pedagógico de Freire em função das demandas do tempo presente, de modo a lançar provocações e possibilidades para o futuro da escolarização no contexto da pandemia. O recorte bibliográfico da obra de Freire (1977; 1980; 1982; 1986; 1987; 1992; 1995; 1996; 1999; 2001; 2005; 2006) se põe em diálogo com estudiosos da obra freiriana (GADOTTI; MELRO; SANTOS NETO), bem como com trabalhos que abordam os desafios da escolarização em tempos de Covid-19 (COSTA; DOWBOR; LIMA et al; MONTEIRO; OTONI; SEVERO; SILVA, VALDERRRAMAS; SOUSA SANTOS, dentre os quais, há autores(as) que dialogam com o pensamento freireano no contexto atual da Covid-19).

\section{Entrelaçamentos do pensamento pedagógico de Paulo Freire na compreensão da complexidade do processo de escolarização em tempos de pan- demia (Covid-19)}

Em tempos de incertezas e transformações,

alguns defendem que a pandemia criará, por ela mesma, uma consciência mais solidária na humanidade. Este cenário seria plausível se fosse possível desconsiderar as relações de poder, os instrumentos de controle e submissão exercidos pela minoria de bilionários sob o conjunto da humanidade. A manifestação da solidariedade esbarra nos interesses reais de quem concentra o poder. (OTONI, 2020, p. 177).

Tal desigualdade igualmente traduziu um quadro crítico no processo de escolarização, uma vez que "costuma-se dizer que as 
desigualdades não nascem na escola e sim que são refletidas nela" (LIMA et al, 2020, p. 07). ${ }^{2}$

Os dados falam por si: por conta de uma combinação de fatores que incidem de maneira desigual tanto sobre a oferta de atividades não presenciais, quanto sobre as condições de acesso e de sua realização, uma criança ou adolescente que vive na região norte do país teve menos da metade da probabilidade de ter realizado, na semana anterior à entrevista, uma atividade escolar não presencial e avançado em seu aprendizado do que seu coetâneo na região Sul. (p. 49).

Segundo Melro (2006), o dever da Educação é, para Paulo Freire, "conscientizar", quer dizer, uma tomada de consciência objetiva e crítica da realidade vivida, a fim de poder ser transformada, uma vez que "ninguém luta contra as forças que não compreende, cuja importância não mede, cujas formas e contornos não discerne (FREIRE, 1980, p. 40).” E a realidade que aqui exige ser transformada é a realidade existencial humana imbuída "de uma fé intensa no homem, fé no seu poder de fazer e refazer, de criar e recriar, fé na sua vocação em ser mais plenamente humano, a qual não é privilégio de uma elite, mas direito inato que têm todos os homens" (FREIRE, 1977, p. 99).

Desde o advento da pandemia (Covid-19), educadores(as) se encontram no modo de trabalho do ensino remoto emergencial. Meses de intenso trabalho docente para o cumprimento das tarefas profissionais, sem perder de vista a função de garantir os processos de aprendizagem dos(as) educandos(as) por trás das telas. Uma avalanche de demandas que provocou, dia após dia, meses após meses, o desequilíbrio cognitivo na base conceitual anteriormente estruturada no desenvolvimento profissional de incontáveis professores(as) da educação básica.

2 Os dados foram coletados da publicação Retratos da Educação, organizado a partir da parceria com diferentes Institutos e Fundações, dentre as quais: Fundação Carlos Chagas; Fundação Lemann; Fundação Roberto Marinho; Itaú Social, etc. Confira em: LIMA, Ana Lúcia D’Império (análise e texto). Retratos da Educação no contexto da pandemia do Coronavírus: um olhar sobre múltiplas desigualdades. Brasil, 2020. 
Frente aos desafios e às necessidades para uma mudança eficaz e efetiva, muitos aprendizados foram impostos e construídos em meio a uma rede de colaboração e parceria no desenvolvimento profissional docente, dentre os quais: adequação na linguagem, nos materiais das aulas, na construção dos conhecimentos, na relação entre educadores(as) e educandos(as), enfim, nos contornos no/ do processo de ensino e de aprendizagem escolar. O tempo de trabalho aumentou em proporção às mudanças na configuração do trabalho docente.

O Ensino Remoto Emergencial é, portanto, uma forma ainda mais precarizada em relação à Educação a Distância, visto que favorece o processo de uberização do professor além de precarizar o ensino. Professores transformaram as suas casas salas de aula, utilizam equipamentos pessoais, dispendem recursos financeiros para arcar com as custas de adequação de espaços para as atividades por meio de vídeoaulas (síncronas ou gravadas), energia elétrica e triplificação do tempo empregado nas atividades docentes como, por exemplo, a preparação de aulas e construção de diferentes atividades - fóruns, questionários online, webquests, chats, videoconferências, avaliações e atendimento aos alunos por meio de wattshap, email, redes sociais e telefone. (COSTA, 2020, p. 11-12).

A despeito de termos vivenciado quase dois anos de tempos pandêmicos, a proposta de ensino remoto na Educação Básica tem muito mais perguntas do que respostas, que nascem de questões que não são de simples resolução. Em 2018, uma pesquisa realizada pelo Centro Regional de Estudos para o Desenvolvimento da Sociedade da Informação (Cetic.br), aponta que 33\% dos domicílios pesquisados não têm acesso a Internet, fato que vem sendo reafirmado pela preocupação expressa por professores e professoras que declaram não ter acesso a Internet com velocidade adequada ao planejamento e implementação de um ensino a distância; e por famílias que não têm condições, especialmente financeiras, para oferecer a seus filhos computador e Internet em casa. Tais condições podem acentuar ainda mais as desigualdades sociais (KNOP, 2017 apud MONTEIRO, 2020). 
Daí a necessidade que tem de ampliar o diálogo - como uma fundamental estrutura do conhecimento - a outros sujeitos cognoscentes. Desta maneira, a aula não é uma aula, no sentido tradicional, mas um encontro em que se busca o conhecimento, e não em que este é transmitido. "Precisamente porque não dicotomiza o seu quefazer em dois momentos distintos: um em que conhece, e outro em que fala sobre seu "conhecimento" - seu quefazer é permanente ato cognoscitivo. Jamais, por isto mesmo, se deixa burocratizar em explicações sonoras, repetidas e mecanizadas" (FREIRE, 1977, p. 79).

Conforme Santos Neto (2004), muitos(as) educadores(as) que estão hoje na prática do cotidiano escolar foram formados dentro de uma tradição que não os estimulou a pensar criticamente. Entre estes, vários viveram na própria carne aquilo que Paulo Freire (1982) chamou de educação bancária: um processo educativo de caráter autoritário no qual o educando não é estimulado a ser autor crítico, mas mero reprodutor. Segundo o autor, quando o(a) educador(a) não tem clareza do projeto que defende, dificilmente consegue ser crítico diante dos projetos que lhe são apresentados. Sem condições de criticar tais projetos, os(as) educadores(as) tornam-se apenas reprodutores da estrutura dominante que explora, nega o humano e a autonomia.

Assim, a reflexão filosófica (antropológica) que se pretenda formadora deverá considerar as histórias concretas dos sujeitos que ali estão e suas necessidades; os processos formativos por eles vivenciados até então; o tipo de cultura escolar no qual foram formados; as exigências do cotidiano no contexto no qual estão vivendo; os determinantes do sistema econômico; as influências advindas dos diferentes segmentos da cultura local, regional e nacional; as pressões originadas das demandas de uma sociedade da informação e da informatização.

Para Santos Neto (2004, p. 09-10), considerar as histórias concretas dos sujeitos significa "fazer emergir os vínculos entre as opções antropológicas (e gnosiológicas, e políticas) e o modo como 
os seres humanos concretos estão construindo a vida em sua prática social; em seguida problematizar tais vínculos; estimular a pensar em suas implicações; sugerir espaços onde novas propostas possam ser criadas e pensadas."

Deve-se ser uma pessoa sobre-humana para ser capaz de prover a resposta pedagógica correta para todos os contextos. $\mathrm{Na}$ verdade, em meu caso, o que venho propondo, a partir de minhas convicções políticas, minhas convicções filosóficas, é um profundo respeito pela autonomia total do educador e da educadora. O que venho propondo é um profundo respeito pela identidade cultural dos alunos e das alunas - uma identidade cultural que implica respeito pela linguagem do outro, pela cor do outro, o gênero do outro, a classe do outro, a orientação sexual do outro, a capacidade intelectual do outro; que implica a habilidade para estimular a criatividade do outro. Mas estas coisas ocorrem em um contexto social e histórico e não no puro ar. Estas coisas ocorrem na história e eu, Paulo Freire, não sou o dono da história. Compreendo a história como possibilidade. (FREIRE, 2001, p. 60).

Para Melro (2006), assumir a educação como ação libertadora é reconhecer que o que está em causa no processo educativo é a vocação ontológica do ser humano - o ser mais - e, por isso, "não pode ser a do depósito de conteúdos, mas a da problematização dos homens em suas relações com o mundo (FREIRE, 1987, p. 67).” Nesse sentido, "a leitura posterior do mundo pode constituir-se de forma mais crítica, menos ingênua, mais rigorosa (FREIRE, 1995, p. 24).”

Humanismo que, recusando tanto o desespero quanto o otimismo ingênuo, é, por isto, esperançosamente crítico. E sua esperança crítica repousa numa crença também crítica: a crença em que os homens podem fazer e refazer as coisas; podem transformar o mundo. Crença em que, fazendo e refazendo as coisas e transformando o mundo, os homens podem superar a situação em que estão sendo um quase não ser e passar a ser um estar sendo em busca do ser mais. (FREIRE, 1977, p. 74).

Como afirma Monteiro (2020), nesse momento essa proposta de ensino a distância na Educação Básica tem muito mais perguntas que respostas. Perguntas que nascem de questões que não são de sim- 
ples resolução. Portanto, a compreensão da complexidade do processo de escolarização em tempos de Covid-19, à luz do pensamento pedagógico de Paulo Freire, nos provoca a pensar sobre a:

[...] importância de compreensão do inédito viável para a assunção da história como possibilidade, em oposição à visão fatalista da realidade. Tal perspectiva, própria da consciência crítica, compreende a historicidade construindo-se a partir do enfrentamento das situações-limite que se apresentam na vida social e pessoal, considerando que os homens e as mulheres assumem atitudes diversas frente às "situações-limites: ou as percebem como um obstáculo que não podem transpor, ou como algo que não querem transpor ou ainda como algo que sabem que existe e que precisa ser rompido e então se empenham na sua superação". O inédito-viável é uma proposta de superação, pelo menos em parte, dos aspectos opressores percebidos na realidade. (FREIRE, 2001, p. 29).

Desta maneira, a compreensão do inédito viável para o enfrentamento e a superação das situações críticas no processo de escolarização em tempos pandêmicos traz a necessidade de reinventarmos as nossas práticas educativas, como sujeitos inseridos e mergulhados nesse processo histórico sem precedentes. E, nessa relação com o mundo, como ato cognoscitivo, que educadores(as) e educandos(as) possam se reconhecer nos seus quefazeres, legitimando, de um lado, o desvelamento da realidade dinâmica e, de outro, a desmistificação dos entraves para um processo de escolarização verdadeiramente humano.

\section{2. (Re)invenções dos processos de escolarização em tempos pandêmicos e a atualidade do pensamento pedagógico de Paulo Freire}

Muitos e diversos foram os fatores que incidiram sobre as possibilidades de cada rede de ensino e de cada escola para planejar e implementar ações e intervenções, visando minimizar os impactos da suspensão das aulas presenciais, dentre os quais:

Características territoriais, condições de infraestrutura, perfil do alunado e especificidades das diferentes etapas de ensino determinaram situações 
marcadamente desiguais entre redes de ensino, impactando na maior ou menor oferta de atividades não presenciais aos estudantes, no volume de atividades oferecidas, bem como as condições de trabalho e de tempo de dedicação dos professores para desenvolvê-las e implementá-las. (LIMA et al, 2020, p. 21). ${ }^{3}$

É fato que nem todos os professores e professoras tiveram formação ou alguma experiência anterior com ensino a distância ou com uso de tecnologias digitais como recurso didático. Nesse contexto: "Como o farão agora, em meio à tensão própria do momento em que vivemos? Como reinventar a própria profissão em meio a uma crise? Como lidar com a angústia que envolve esse momento diante do não saber fazer, do desconhecido?” (MONTEIRO, 2020, p. 245).

Neste contexto, "educador e educandos se arquivam na medida em que, nesta distorcida visão da educação, não há criatividade, não há transformação, não há saber. Só existe saber na invenção, na reinvenção, na busca inquieta, impaciente, permanente, que os homens fazem no mundo, com o mundo e com os outros. Busca esperançosa também" (FREIRE, 2005, p. 66-67). Dito de outra forma, "liberdade com responsabilidade, certamente, é a coragem de sermos nós mesmos, de colocar em cena nossos valores, de sairmos da condição de passividade e (re)inventar uma educação possível em tempos de pandemia" (MONTEIRO, 2020, p. 248).

Nosso pensamento e entendimento é de que esse ensino a distância deve-
ria se constituir em uma oportunidade de manter uma comunicação ativa
entre escola e família, entre professores, professoras e estudantes, de for-
ma a criar uma rede de proteção e acolhimento nesse momento de crise
que afeta a todos nós, indistintamente. Mas será que é isso que está acon-
tecendo? Esse questionamento se faz pertinente, pois o que temos visto,
lido e ouvido nas redes sociais são professores e professoras inquietos,

Publicação Retratos da Educação, organizado a partir da parceria com diferentes Institutos e Fundações, dentre as quais: Fundação Carlos Chagas; Fundação Lemann; Fundação Roberto Marinho; Itaú Social, etc. Confira em: LIMA, Ana Lúcia D’Império (análise e texto). Retratos da Educação no contexto da pandemia do Coronavírus: um olhar sobre múltiplas desigualdades. Brasil, 2020. 
angustiados, estressados e até mesmo desesperançados por não saber o que fazer, como fazer, quando fazer e até mesmo o porquê fazer. (MONTEIRO, 2020, p. 245-246).

Reinventar o pensamento pedagógico de Paulo Freire significa aceitar sua proposta de encarar a história como possibilidade. Desse modo, o assim chamado educador(a) freireano(a), que se recusa a reinventar a obra de Freire, está simultaneamente negando a história como uma possibilidade e procurando pela certeza de aplicações técnicas. Para Freire (2001), tal educador(a) precisa reavaliar sua postura diante da proposta teórica que o mesmo autor fez durante os últimos 35 anos.

Este assim chamado educador(a) freireano(a), se verdadeiramente deseja entender o pensamento de Freire, deve igualmente buscar uma pedagogia "que tem de ser forjada com ele e não para ele, enquanto homens e povos, na luta incessante de recuperação de sua humanidade."

[...] muitos dos educadores(as) que me utilizam de modo superficial como um meio para resolver seus problemas técnicos pedagogicamente são, em certo sentido, turistas freireanos. Eles quase se tornam fundamentalistas freireanos, e então o mundo torna-se fixo, eliminando-se a possibilidade de a história ser uma possibilidade. O que eu proponho é precisamente o oposto. A história é sempre uma possibilidade e não fixada ou predeterminada. Igualmente, o educador(a) progressista deve estar sempre em mudança, continuamente reinventando-me e reinventando o que significa ser democrático em seu próprio contexto específico cultural e histórico. (FREIRE, 2001, p. 61).

Freire (2006) defendia que uma escola pública popular não é apenas à qual todos têm acesso, mas aquela de cuja construção todos podem participar, aquela que atende realmente aos interesses populares que são os interesses da maioria. Portanto, é uma escola com uma nova qualidade "baseada no compromisso, numa postura solidária, formando a consciência social e democrática. Nela todos os agentes, e não só os professores, possuem papel ativo, dinâmico, experimentando novas formas de aprender, 
de participar, de ensinar, de trabalhar, de brincar e de festejar" (FREIRE, 2006, p. 298).

Para Freire (1999, p. 30 apud MELRO, 2006, p. 03), "uma educação sem esperança não é educação. Quem não tem esperança na educação [...] deverá procurar trabalho noutro lugar”. Se conseguirmos, apesar dos tempos pandêmicos sombrios, apesar de tudo, manter ou construir a esperança, já estaremos, segundo Freire (1997), agindo nesse processo de (re)invenção dos processos de escolarização.

Como afirma Melro (2006), o futuro exige, com Freire, a construção de um conhecimento transformador da realidade, operando mudanças de forma efetiva, tendo por base as diferenças e a singularidade de cada ser humano. Só nos restam dois caminhos a seguir: ou saímos da rotina como Freire nos sugere e buscamos inovar a escola e com ela a prática pedagógica, ou ficamos eternamente a discutir que a mesma não é viável, pondo responsabilidade no sistema de ensino, nos ombros do governo, na família e em outros setores da sociedade. Desse modo, há que ser responsável individual e coletivamente, e passar do discurso à ação, da teoria à prática, bem como da utopia à realidade, em toda sua plenitude (FREIRE, 1982).

A solidariedade social e política de que precisamos para construir a sociedade menos feia e menos arestosa, em que podemos ser mais nós mesmos, tem na formação democrática uma prática de real importância. A aprendizagem da assunção do sujeito é incompatível com o treinamento pragmático ou com o elitismo antoritário dos que se pensam donos da verdade e do saber articulado. (FREIRE, 1996, p.42).

Segundo Freire e Shor (1986), os que aceitam a tarefa da transformação social têm um sonho, embora também tenham grande quantidade de obstáculos pela frente. Por causa disso, o(a) educador(a) libertador(a) tem que criar inserido na prática, aprendendo os limites concretos de sua ação, esclarecendo-se sobre as possibilidades, não muito aquém nem muito além de nossos limites do medo necessário. 
A maior parte dos que trabalham em salas de aula sabe que a docência exige muito de nós. É, também, uma atividade muito prática, embora tudo que ocorre em classe seja a ponta de um iceberg teórico. Mas os professores se interessam mais pela prática do que pela teoria. Apesar de toda prática ter um fundamento teórico e vice-versa, a maioria das pesquisas em educação não é de muita ajuda nas horas agitadas da sala de aula concreta. Os professores enfrentam aulas demais, alunos demais, e controle administrativo demais de tal modo que a necessidade de alguma coisa que funcione em classe é muito maior do que uma aparente necessidade de teoria. Entretanto, as preocupantes falhas do sistema escolar exigem novas idéias [ideias]. Até mesmo professores sobrecarregados de trabalho têm curiosidade a respeito de alternativas. Querem saber como usá-las em classe, se o método do diálogo pode ser importante em sala de aula. (FREIRE; SHOR, 1986, p. 12).

Conforme o pensamento pedagógico de Freire (1977; 1980; 1982; 1986; 1987; 1992; 1995; 1996; 1999; 2001; 2005; 2006), o que se pretende com o diálogo não é que o(a) educando(a) reconstitua todos os passos dados até hoje na elaboração do saber científico e técnico.

[...] o que se pretende com o diálogo, em qualquer hipótese (seja em torno de um conhecimento científico e técnico, seja de um conhecimento experiencial), é a problematização do próprio conhecimento em sua indiscutível reação com a realidade concreta na qual se gera e sobre a qual incide, para melhor compreendê-la, explicá-la, transformá-la. (FREIRE, 1977, p. 51-52).

Conforme Santos Neto (s/d, p. 01-02), "a escola precisa fazer com os educandos o caminho que evolui da informação ao conhecimento e deste à sapiência, ajudando-os a prepararem-se para dialogar na complexidade e na incerteza." Neste caminho, "a criação de novos projetos no campo da educação requer [...] a definição de fundamentos consistentes sobre os quais seja possível arriscar a construção de novas propostas."

É necessário re-pensar as finalidades com as quais se realiza a educação escolar. Os desconfortos, os incômodos e os conflitos no interior da escola apontam para uma inadequação da mesma aos tempos atuais. Um 
certo paradigma de organização escolar parece estar se esgotando e vai tornando-se cada vez mais urgente a necessidade de re-inventar a escola e suas formas de organização;

Neste processo de re-inventar a escola será necessário pensar outros espaços escolares, outros tempos e, portanto, um currículo que, em permanente construção, esteja aberto a atender às necessidades dos seres humanos, complexos, que vivem seu processo educativo no interior da escola; Assim, a reprodução de propostas escolares do passado não satisfaz às necessidades do presente. É urgente criar novas propostas escolares, ressignificar o lugar da escola e o tipo de contribuição que a educação escolar pode dar às diferentes comunidades e aos diferentes sujeitos humanos... (SANTOS NETO, s/d, p. 05-06).

A releitura da obra de Paulo Freire, por diferentes olhares, nos fortalece para a reinvenção de seu pensamento pedagógico, tão atual e atemporal, na medida em que "o sonho é assim uma exigência ou uma condição que se vem fazendo permanente na história que fazemos e que nos faz e re-faz."

[... precisamos reacender o sonho de ser professor com sentido, justamente para combater esse estado de coisas. Precisamos reafirmar o sonho justamente, como nos diz Paulo Freire, para fazer frente "à malvadez neoliberal, ao cinismo de sua ideologia fatalista e a sua recusa inflexível ao sonho e à utopia”. Sair do plano ideal para a prática, não é abandonar o sonho para agir, mas agir em função dele, agir em função de um projeto de vida e de escola, de cidade, de mundo possível, de planeta... um projeto de esperança. (GADOT'TI, 2003, p. 49-50).

Segundo Freire (2001, p. 19), "precisamos, urgentemente, pois, reavivar em nós mesmos a nossa capacidade ontológica de sonhar, de projetar para um futuro mais próximo possível dias de paz, equidade e solidariedade." Sonhar coletivamente é, pois, "um desafio que se coloca a todos(as) que lutam pela reinvenção da educação, na perspectiva de sua democratização, na escola e em outros espaços educativos" (FREIRE, 2001, p. 31). 


\section{Considerações finais, porém... transitórias e provisórias}

Não há amanhã sem projeto, sem sonho, sem utopia, sem esperança, sem o trabalho de criação e desenvolvimento de possibilidades que viabilizem a sua concretização.

É neste sentido que tenho dito em diferentes ocasiões que sou esperançoso não por teimosia, mas por imperativo existencial.

Paulo Freire

As pandemias mostram de maneira cruel como o capitalismo neoliberal incapacitou o Estado para responder às emergências. As respostas que estão a dar à crise sanitária variam de Estado para Estado, mas nenhum deles pode disfarçar a sua incapacidade, assim como a sua falta de previsibilidade em relação a emergências que anunciadas como de ocorrência próxima e muito provável. Sousa Santos (2020) está certo de que as lições que os tempos pandêmicos dão/darão para a humanidade são/serão de forma cruel, desafiando os homens a refletir se são/serão capazes de aprender as lições e pensar em soluções inéditas e viáveis.

Segundo Dowbor (2020), o que temos pela frente, além do Coronavírus, é pensar uma sociedade mais solidária e resiliente, em cada país e em cada cidade. Uma outra dimensão capaz de ultrapassar a pandemia e apontar novos rumos é o desafio da governança planetária, uma vez que, conforme Sousa Santos (2020), a humanidade está mergulhada em outras quarentenas anteriores à quarentena da Covid-19, na medida em que vem negligenciando a natureza e a consciência planetária, em prol de interesses e demandas da quarentena do capitalismo. Assim, futuramente, estaremos mais preparados das quarentenas provocadas por pandemias quando a humanidade superar a quarentena do capitalismo, revertendo tal lógica em função de nossa condição humana de dependência ao planeta Terra.

Para Otoni (2020), a denúncia de Sousa Santos requer uma ação política na esperança por apostas futuras no enfrentamento 
de um cenário incerto e limitado. Da mesma maneira, anuncia a necessidade de mudança na postura dos homens diante de cenários de crise, uma vez que as profundas transformações são viabilizadas quando encontram forças sociais capazes de explorar as crises quarentenas - como oportunidades.

Paulo Freire nos alertava para a necessidade de nos pormos em relação de organicidade com nossa realidade, a fim de que possamos equacionar nossos problemas de forma crítica e consciente, haja vista que somente na medida em que nos fizermos íntimos de nossos problemas, sobretudo de nossas causas e de seus efeitos, nem sempre iguais aos de outros espaços e de outros tempos, ao contrário, quase sempre diferentes, poderemos apresentar soluções para eles. Como se verifica, tal relação de organicidade com uma realidade específica é fundamental, na medida em que nos mune de critérios e fundamentos para, antes de apresentar soluções, identificar uma experiência/vivência problematizadora.

Paulo Freire sonhava com uma sociedade, um mundo, onde todos coubessem. A educação pode dar um passo na direção deste outro mundo possível se ensinar as pessoas com um novo paradigma do conhecimento, com uma visão do mundo onde todas as formas de conhecimento tenham lugar. Nas palavras de Gadotti (2003), é preciso assumir uma concepção de conhecimento que se constitui no pluralismo de ideias, de saberes e de conhecimentos da humanidade, formando os seres humanos por meio de uma postura de generosidade epistemológica, em busca da construção de uma outra sociedade possível.

Na esteira dessas ideias, Santos Neto (2004) acreditava que a educação é a explicitação de uma certa maneira de compreensão do ser humano, ou seja, a concepção antropológica assumida pelos(as) educadores(as) implica uma certa concepção de educação (no campo formal, não-formal e informal) e, nesse sentido, os processos educativos podem ser aperfeiçoados na medida em que os(as) educadores(as) tiverem maior clareza antropológica.

A educação é um processo no qual seres humanos, vão se construindo enquanto seres humanos. Nesse processo educativo acontece o encontro de crianças, jovens, homens e mulheres para 
construir saberes práticos e políticos, necessários ao desenvolvimento da vida, bem como os saberes necessários à construção de sentido para a existência humana. A reflexão antropológica pode contribuir decisivamente para o sucesso deste processo, na medida em que a educação deve assumir o ser humano como objeto central de processos molhados de esperança e, portanto, de humanização (SANTOS NETO, 2004).

Monteiro (2020) alerta que não podemos abrir mão da esperança, na medida em que é possível que não apenas em um, mas em vários momentos desta caminhada, sejamos surpreendidos por um cansaço existencial, como bem nos alertou Paulo Freire, quando também esteve em uma situação de adversidade, na qual sofreu o exílio do próprio país. Assim como Freire, não podemos abrir mão da esperança, da fé e da crença no ser humano.

A sociedade da informação e do conhecimento consolida suas bases conceituais, de mãos dadas com as novas tecnologias da informação e da comunicação. A inovação, tão anunciada e gestada, tornou-se meio para o enfrentamento dos desafios e das demandas dos dias atuais, em tempos pandêmicos da Covid-19.

Nesse contexto de uso intenso das tecnologias, de interação, de comunicação e de construção de diferentes linguagens, há, simultaneamente, a exposição de fragilidades, de preconceitos, de atitudes e comportamentos que beiram a perplexidade do inacreditável... Os "atos falhos" trazem à tona a verdadeira face desumana, em meio a uma "sociedade líquida" e à deriva, em tempos de incerteza, de dores comuns e dores únicas.

As máscaras caem e revelam um universo de sombras, bem como, em tempos pandêmicos de apologia ao uso de máscaras, urge a esperança por uma educação que dialogue com os fundamentos ontológicos do pensamento pedagógico de Paulo Freire.

Em tempos de instabilidade, insegurança, impermanência... as demandas se intensificam proporcionalmente aos apelos continuados por mudanças e transformações em nossas atitudes e ações. Em tempos pandêmicos, a necessidade de mudança e de transfor- 
mação se impõem e atravessam nossa condição humana de existência. Somos atravessados por múltiplas determinações que nos impulsionam a fazer escolhas.

$\mathrm{Na}$ esteira dessas ideias, podemos concluir que o pensamento pedagógico de Paulo Freire é atual e atemporal, uma vez que confere sustentação teórica e prática aos educadores com esperança por tempos de superação dos desafios em contextos pandêmicos e pós-pandêmicos de escolarização.

Que possamos continuar acreditando na transformação de nossas práticas pedagógicas em contextos de escolarização e Covid-19, em busca permanente e esperançosa por tempos melhores. Que possamos encontrar, no pensamento pedagógico de Paulo Freire, a sustentação teórica e prática que suscite esperança por tempos de transformação e superação dos desafios e enfrentamentos em contextos pandêmicos e pós-pandêmicos de escolarização. Afinal, "há saídas, possibilidades e esperança..." (SANTOS NETO, 2004, p. 11). Que as (in)certezas que estão ao alcance das urgências dos tempos pandêmicos atuais, possam concretizar as crenças e os projetos educativos para um futuro no qual a educação seja prioridade.

\section{Referências}

COSTA, Claúdia Lúcia da. Educação em tempos de pandemia: ensino remoto emergencial e avanço da política neoliberal. Revista Expedições, Morrinhos/GO, v.11, Fluxo Contínuo, jan./dez., 2020. ISSN: 2179-6386

Disponível em: https://www.revista.ueg.br/index.php/revista geth/article/ view/11057/7836 Acesso em: 10.09.2021

DOWBOR, Ladislau. Além do corona vírus. In: TOSTES, Anjuli; FILHO, Hugo Melo. Quarentena: reflexões sobre a pandemia e depois. Bauru: Canal 6, 2020. Recurso digital - (Projeto Editorial Praxis), p. 113-120. Disponível em: http:// editorapraxis.com.br/quarentena/ Acesso em: 10.09.2021

FREIRE, Paulo. Extensão ou comunicação? Rio de Janeiro: Paz e Terra, 1977.

FREIRE, Paulo. Conscientização, Teoria e Prática da Libertação. São Paulo: Moraes, 1980.

FREIRE, Paulo. Educação: o sonho possível. Rio de Janeiro: Graal, 1982. 
FREIRE, Paulo; SHOR, Ira. Medo e Ousadia: o Cotidiano do Professor. Rio de Janeiro: Paz e Terra, 1986.

FREIRE, Paulo. Pedagogia do Oprimido. São Paulo: Paz e Terra, 1987.

FREIRE, Paulo. Pedagogia da Esperança: um reencontro com a Pedagogia do oprimido. Notas de Ana Maria Araújo Freire. São Paulo: Paz e Terra, 1992.

FREIRE, Paulo. “À sombra desta mangueira”. In: FREIRE, Paulo. À sombra desta mangueira. São Paulo, SP: Olho D’água, 1995.

FREIRE, Paulo. Pedagogia da autonomia: saberes necessários à prática educativa. São Paulo: Paz e Terra, 1996 - (Coleção Leitura).

FREIRE, Paulo. Pedagogia da Esperança: um reencontro com a Pedagogia do Oprimido. Rio de Janeiro: Paz e Terra, 1999.

FREIRE, Paulo; FREIRE, Ana Araújo Freire (org.). Pedagogia dos sonhos possíveis. São Paulo: Editora UNESP, 2001. ISBN: 85-7139-372-9

FREIRE, Paulo. Pedagogia do Oprimido. Rio de Janeiro: Paz e Terra, 2005. ISBN: 85-219-0005-8

FREIRE, Ana Maria Araújo. Paulo Freire: uma história de vida. Indaiatuba, SP: Villa das Letras, 2006.

GADOTTI, Moacir. Boniteza de um sonho: Ensinar-e-aprender com sentido. São Paulo: Grubhas, 2003.

LIMA, Ana Lúcia D’Império (et al). Retratos da Educação no contexto da pandemia do Coronavírus: um olhar sobre múltiplas desigualdades. Brasil, 2020. Disponível em: https://frm.org.br/wp-content/uploads/2021/02/Retratos-da-Educacao-na-Pandemia_digital-1-compactado.pdf

Acesso em 10.09.2021

MELRO, Joaquim. Quando educar é libertar. Uma Reflexão Crítica em Torno do Pensamento Pedagógico de Paulo Freire. In: D. Machado; E. Macedo; H. Borges; J. Mafra; L. Cortesão; M. Mendes; M. Tavares... R. Trindade (Eds.). Actas IV Encontro Internacional do Fórum Paulo Freire. Caminhando para uma cidadania multicultural (s/p). Porto: Instituto Paulo Freire - Portugal \& Universidade do Porto. (Suporte CdRom). 2006. 
MONTEIRO, Sandrelena da Silva. (Re)inventar educação escolar no Brasil em tempos da Covid-19. Revista Augustus, Rio de Janeiro, v.25, p. 237-254, jul./out. 2020. Recurso digital. ISSN: 1981-1896 Disponível em: https://apl.unisuam.edu. br/index.php/revistaaugustus/article/view/552 Acesso em: 10.09.2021

OTONI, Pedro. Presente e futuro: sete apontamentos. In: MELO FILHO, Hugo; TOSTES, Anjuli. Quarentena: reflexões sobre a pandemia e depois. Bauru: Canal 6, 2020. Recurso digital - (Projeto Editorial Praxis), p. 171-180. Disponível em: http:/ / editorapraxis.com.br/quarentena/ Acesso em: 10.09.2021

SANTOS NETO, Elydio dos. Filosofia e Prática Docente: fundamentos para a construção da concepção pedagógica do professor e do projeto político-pedagógico na escola. Trabalho apresentado no II Encontro Internacional de Filosofia e Educação - Fórum Sudeste do Ensino de Filosofia: "Políticas do ensino de Filosofia”. UERJ - Rio de Janeiro, 9 a 11 de setembro de 2004. Texto completo publicado nos Anais do II Encontro Internacional em CD-ROM. ISBN 85-904753-1

SANTOS NETO, Elydio dos. Desafios para a escola boje: um olhar desde Paulo freire e Edgar Morin. s/d.

SEVERO, Valdete Souto. Sobre a Covid-19 e as nossas escolhas. In: TOSTES, Anjuli; FILHO, Hugo Melo. Quarentena: reflexões sobre a pandemia e depois. Bauru: Canal 6, 2020. Recurso digital - (Projeto Editorial Praxis), p. 219-226. Disponível em: http:/ /editorapraxis.com.br/quarentena/ Acesso em: 10.09.2021

SILVA, Cristiane Samária Gomes da; VALDERRAMAS, Edgard Luiz Bernardes; BASILIO, Patrícia Cristina de Souza; FERRARI, Pollyana. Educação: reinvenções e absurdos em tempos da Covid-19. Raízes e Rumos, Rio de Janeiro, v.8, n.1, p. 69-86, jan.-jul., 2020. Disponível em: http://seer.unirio.br/raizeserumos/article/ view/10294 Acesso em: 10.09.2021

SOUSA SANTOS, Boaventura de. A cruel pedagogia do vírus. Coimbra: Edições Almedina, 2020. Recurso digital. ISBN: 978-972-40-8496-1 Disponível em: https://www.abennacional.org.br/site/wp-content/uploads/2020/04/Livro_ Boaventura.pdf Acesso em: 10.09.2021 